\section{IMF Working Paper}

(C) 1998 International Monetary Fund
This is a Working Paper and the author(s) would welcome any comments on the present text. Citations should refer to a Working Paper of the International Monetary Fund. The views expressed are those of the author(s) and do not necessarily represent those of the Fund

WP/98/92

INTERNATIONAL MONETARY FUND

Research Department

\title{
Asymmetric Information and the Market Structure of the Banking Industry
}

Prepared by Giovanni Dell' Ariccia ${ }^{1}$

Authorized for distribution by Donald Mathieson

June 1998

\begin{abstract}
The paper analyzes the effects of informational asymmetries on the market structure of the banking industry in a multi-period model of spatial competition. All lenders face uncertainty with regard to borrowers' creditworthiness, but, in the process of lending, incumbent banks gather proprietary information about their clients, acquiring an advantage over potential entrants. These informational asymmetries are an important determinant of the industry structure and may represent a barrier to entry for new banks. The paper shows that, in contrast with traditional models of horizontal differentiation, the steady-state equilibrium is characterized by a finite number of banks even in the absence of fixed costs.

JEL classification numbers: D43, D82, G21
\end{abstract}

Keywords: Loan Market, Barriers to Entry, Spatial Competition

Author's E-mail address: gdellariccia@imf.org

\footnotetext{
${ }^{1}$ An earlier version of this paper was part of my $\mathrm{Ph} . \mathrm{D}$. thesis at MIT and has been submitted to an outside journal. I would like to thank Rudi Dornbusch, Bengt Holmstorm, Vincent Hogan, Pietro Garibaldi, Jean Tirole, Jaume Ventura, and the participants in seminars at MIT, Columbia University, University of Stockholm IIES, Stockholm School of Economics, ESSEC, and Università Bocconi for their useful comments and suggestions. I am particularly grateful to Ezra Friedman and Robert Marquez for their comments and the discussions we had about this paper. Financial support by Compagnia di San Paolo and BNL is gratefully acknowledged. All errors are mine.
} 
Contents

Page

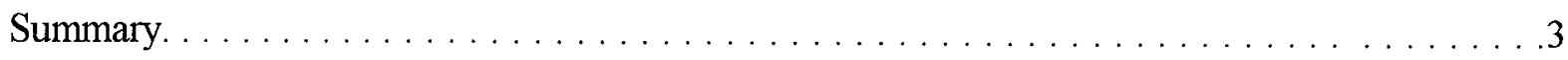

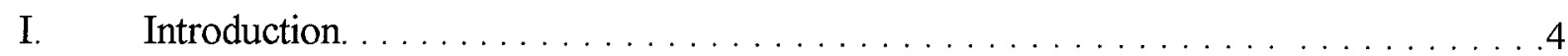

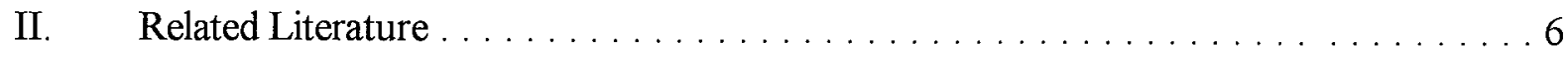

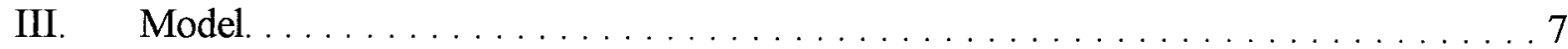

A. Short-Run Equilibrium . . . . . . . . . . . . . . . . . . . . . . . . 10

B. Steady State Market Structure . . . . . . . . . . . . . . . . . . . . . . 14

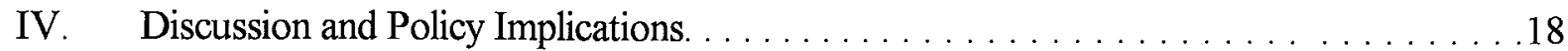

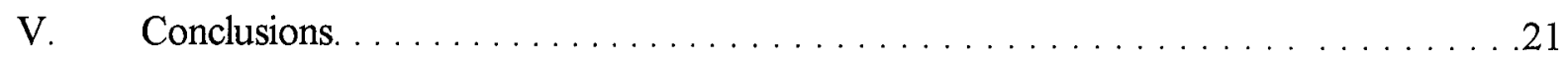

Appendices

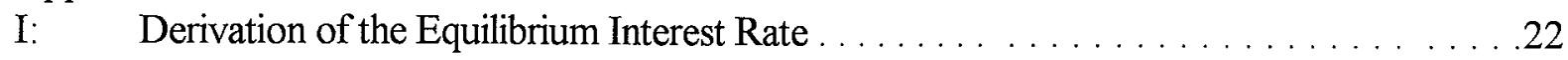

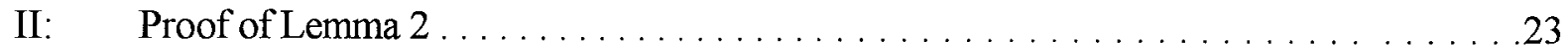

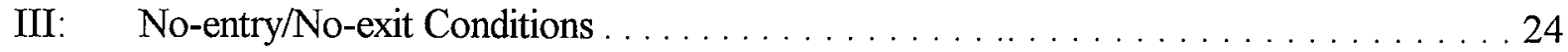

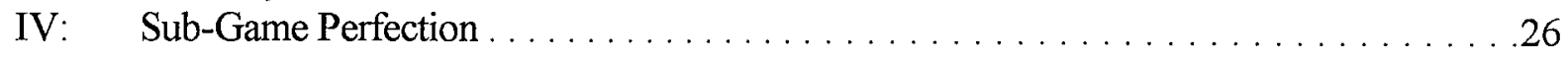

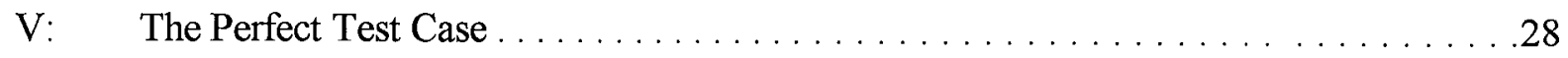

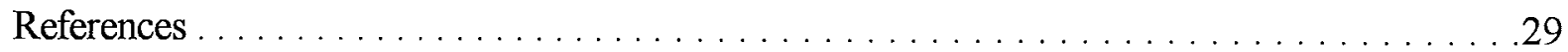




\section{SUMMARY}

A large literature has identified asymmetric information as the defining characteristic of credit markets. Lenders offering credit to borrowers face uncertainty about their creditworthiness to the extent that they cannot observe some of the borrowers' characteristics and actions. These informational asymmetries cause adverse selection and moral hazard problems and may invalidate standard competitive market results. However, over time, lenders resolve part of these informational problems. In the process of lending, financial intermediaries are able to gather some proprietary information about borrowers' creditworthiness. Hence, they acquire some degree of informational monopoly about their clients and thus market power. Unable to signal their quality to competing lenders, creditworthy borrowers are locked in a bank-client relationship and are forced to pay interest rates above the competitive level.

The paper examines the role of asymmetric information in the determination of the equilibrium structure of loan markets in the context of a multi-period model of spatial competition. In particular, it endogenizes banks' entry and exit decisions and investigates whether informational asymmetries in the banking industry can create a barrier to entry for new lending institutions. Learning by lending provides incumbent banks with an informational advantage that may become an important determinant of the industry structure. Hence, potential entrants may face adverse selection problems more severe than those faced by incumbents for their lesser ability to discriminate among borrowers. In this context, the paper shows that asymmetric information generates an adverse selection effect that acts as a barrier to entry, preventing new lenders from entering the market. Moreover, this incumbent advantage is larger in markets where asymmetric information is more important. Technically, the paper shows that, even in the absence of fixed costs, the market sustains only a limited number of banks in equilibrium. This represents a new and non-standard result for the literature on product differentiation. 


\section{INTRODUCTION}

A large literature has identified asymmetric information as the defining characteristic of credit markets. ${ }^{1}$ Lenders offering credit to borrowers face uncertainty about their creditworthiness to the extent that they cannot observe some of the borrowers' characteristics and actions. These informational asymmetries lead to credit rationing equilibria (e.g., Stiglitz and Weiss, 1981), and may invalidate other standard competitive market results (e.g., Broecker, 1990). ${ }^{2}$ However, over time, lenders resolve part of these informational problems. In the process of lending, financial intermediaries are able to gather some proprietary information about borrowers creditworthiness. Hence, they acquire some degree of informational monopoly about their clients and thus market power. ${ }^{3}$ Unable to signal their quality to competing lenders, creditworthy borrowers are locked in a bank-client relationship and are forced to pay interest rates above the competitive level. A recent literature has examined the consequences of this informational structure on banking competition (e.g., Sharpe, 1990) and borrowers incentives (Padilla and Pagano, 1997). ${ }^{4}$ However, little attention has been paid to the analysis of the effects of asymmetric information on the structure of the banking industry. This paper is an attempt in that direction.

In this paper we examine the role of asymmetric information in the determination of the equilibrium structure of loan markets. In particular, we endogenize banks' entry/exit decisions and investigate the possibility that informational asymmetries in the banking industry can create a barrier to entry for new lending institutions. We consider a situation where over time lenders are able to obtain some proprietary information about their clients. Potential entrants may then face adverse selection problems more severe than those faced by incumbents for their lesser ability to discriminate among borrowers. Hence, learning by lending provides incumbent banks with an informational advantage that may become an important determinant of the industry structure. In this context, we show that asymmetric information generates an adverse selection effect that acts as a barrier to entry, preventing new lenders from entering the market. We also show that this adverse selection problem is less severe in markets that are more dynamic. In other words, we show that entry is easier in markets characterized by a higher growth rate of the borrower population.

\footnotetext{
${ }^{1}$ See Bhattacharya and Thakor (1993), or Van Damme (1994) for a comprehensive survey of the literature.

${ }^{2}$ Broecker (1990) shows that not necessarily the equilibrium interest rate decreases with the number of lenders competing in the market.

${ }^{3}$ See Greenbaum, Kanatas, and Venezia (1989).

${ }^{4}$ Sharpe (1990) show that under this informational structure banks will fight for market share in the hope of future monopolistic profits. Padilla and Pagano (1997) argue that the perspective of rent extraction induce moral hazard on the part of borrowers, providing an incentive for information sharing among banks.
} 
In the paper we develop these ideas in the context of a multi-period model of spatial competition, where entry-exit decisions are endogenous. Formally, we show that in equilibrium there is a finite number of competitors even in the absence of an exogenous fixed cost. This equilibrium contrasts with the traditional spatial competition outcome and it represents a new result for the literature on product differentiation. ${ }^{5}$ In our model adverse selection generates an "endogenous" fixed cost that limits the number of banks the market can sustain in equilibrium.

To fix the intuition consider the following scenario. Banks offering loans to applicant firms always face an asymmetric information problem to the extent that managers and/or owners know their firms better than the banks do. However, this problem does not have to be of the same magnitude for all banks and for all categories of firms. On the one hand, borrowers can be characterized by different degrees of informational asymmetries. It may be that the difficulties of evaluating the credit worthiness of a firm differ across industries and/or firms, or that some agents are able to provide more collateral and guarantees, diminishing the importance of informational asymmetries. ${ }^{6}$ On the other hand, asymmetric information may arise between agents that are on the same side of the market. Some financial institutions may find themselves in a situation of informational advantage (disadvantage). In the screening and monitoring processes associated with their lending activity banks are likely to gather some private information about their clients' credit-worthiness. Hence, banks may be able to better distinguish "good" borrowers from "bad" among those with whom they have already established a previous lending relationship, than among borrowers that are new and unknown to them. In this context, potential entrants into a loan market suffer an adverse selection problem stemming from their lesser ability to determine whether applicant borrowers are new borrowers seeking financing for their untested project or "bad" borrowers rejected by an incumbent bank. The result of this informational asymmetry is that entrant lenders face a "worse" distribution of applicant borrowers than incumbent banks. This puts entrants into a worse position relative to incumbents, and may lead to diminished or deterred entry. In this context it is easy to see why informational entry barriers will be lower in markets where the borrower population grows more rapidly. The incumbent banks' advantage depends on the specific knowledge they have acquired about their clients. Hence, the adverse selection problem that entrant are facing will diminish as the share of new borrowers in the market rises, and thus, it will be smaller in faster growing markets.

The analysis in this paper is relevant from a regulatory standpoint. One implicit prediction of our model is that any deregulation process aimed to increase competition in the banking industry is more likely to induce entry on those segments of the market where asymmetric information is less important. As suggested by Vives (1991), the increase in

\footnotetext{
${ }^{5}$ See Salop (1979) and Sutton (1991).

${ }^{6}$ For example, there might be economies of scale in acquiring information about individual firms, so that lending to small firms involves a higher "information cost" per dollar borrowed.
} 
competition will not be uniform. Different degrees of competition will prevail on different segments of the market, and the effects of financial integration will be different for different categories of borrowers. As a consequence the deregulation process could benefit some borrowers more than others. Moreover, it could hurt some classes of borrowers to the extent that the new structure of the banking industry reallocates funds away from them. In this context, this paper offers a partial explanation for the merger activity in the banking sector. "Out of market" mergers or acquisitions, in which a bank buys a lending institution operating in a different market, might represent a way to overcome the informational barriers described above. By buying an existing bank, the entrant may be able to acquire the specific knowledge of that bank about its portfolio of clients, and avoid the adverse selection problems associated with direct entry. However, from the regulator point of view, this kind of entry does not change the total number of banks on the market and thus it does not have a pro-competitive effect. ${ }^{7}$

The paper proceeds as follows. Section 2 reviews some related literature. Section 3 describes the model. Section 4 comments the model's results and analyzes some policy implications. Section 5 concludes.

\section{RElated Literature}

A recent literature has addressed related issues of asymmetric information and the effects of competition in banking. Broecker (1990) analyzes a market for credit where banks compete Bertrand style on the basis of the interest rate. He shows that when banks perform independently an imperfect test to screen the credit-worthiness of applicants, the equilibrium loan interest rate can be increasing with the number of banks in the market. The intuition behind this result is that the average credit-worthiness of applicant firms that pass the test with at least one bank is decreasing with the number of banks. Riordan (1992) offers an analysis similar to that in Broecker (1990) using an application of auction theory. Hoff and Stiglitz (1997) obtain a related result analyzing the effect of credit subsidies. In their model it is moral hazard rather than adverse selection that drives the interest rate up when competition increases. If the information flow worsens with the number of competitors, reputation effects and borrowers' incentives to repay become weaker in more competitive markets. Hence, entry by new lenders implies more severe moral hazard problems and increases enforcement and monitoring costs, leading to higher interest rates. Sharpe (1990) concentrates on the notion that high quality firms are "informationally captured" by their own bank: when creditworthy firms find it difficult to signal their quality to other banks, adverse selection makes it difficult for banks to "steal" each others good customers without attracting the bad ones as well. Banks will then offer low introductory rates because asymmetric information enables them to extract surplus from their good firms in future periods. Petersen and Rajan (1995) show

${ }^{7}$ If anything the effect could be the opposite. See multi-market competition literature, Tirole (1988). 
that banks' willingness to lend to new "unknown" firms increases with the banking market concentration, while the interest rate charged decreases. The intuition is that as banks' market power increases, they can extract a larger share of the future surplus from borrowers. In other words, the value of lending relationships diminishes with the degree of competition among banks. $^{8}$ Dell'Ariccia, Friedman and Marquez (1997), with an analysis similar to this paper, show that informational asymmetries in the banking industry can be a barrier to entry by themselves. They show that in a mono-period Bertrand setting asymmetric information leads to a result of blockaded entry. ${ }^{9}$ The aim of the model in this paper is to develop that idea in a dynamic context with differentiated products. The motivation is twofold. First, entry (exit) is primarily a dynamic issue that can be better understood in a dynamic multi-period setting. Second, Bertrand games represent an extreme form of competitive interaction that does not allow us to consider setups with different degrees of competition.

\section{MODEL}

We consider an economy where banks interact strategically in a non perfectly competitive market. The formal setup is a multi-period version of a model of spatial competition à là Salop, in which lenders/banks compete in the interest rate for loans to borrowers/firms (in what follows we will use the terms firm, borrower, and entrepreneur interchangeably). ${ }^{10}$ This framework has two attractive features. First, it introduces product differentiation, making each bank's demand function continuous in both its own and its competitors interest rates, and allowing the existence of pure strategy equilibria. Second, it provides each bank with some market power, enabling us to examine intermediate oligopolistic

\footnotetext{
${ }^{8}$ Petersen and Rajan (1995) do not model explicitly the interaction among banks. In their paper "market power" is an exogenous variable.

${ }^{9}$ Some analogies can be found between this paper and Greenwald (1986) that analyzes the effects of asymmetric information on the labor market. Another somehow related paper is Hendricks, Porter and Wilson (1994). They analyze auctions where one informed buyer who observes some private signal, and an uninformed buyer, bid for an object of unknown value.

${ }^{10}$ In the Salop's model consumers with a unit demand are uniformly distributed around a circle of measure one, that represents the space of product varieties. Producers are located equidistant around the circle, so that maximal differentiation is exogenously imposed. Given this location producers compete in price for customers. Consumers have a transportation cost $\tau$ per unit of length. Thus the total cost of buying one unit of product is the sum of price and transportation cost. An individual consumer is indifferent between two producers when the total costs are equalized. For an application to banking, see Chiappori et al.(1995), and Besanko and Thakor (1992), while Matutes and Vives (1996) use a standard Hotelling model.
} 
industry structures. ${ }^{11}$ In what follows we exclude multi-branch competition. In other words, we rule out the possibility that more than one bank belongs to the same owner, or that banks can form cartels. Multi-branch competition would be technically much more complex and it would not add much to the intuition. Moreover, entry would be more difficult in a multi-branch setting. Hence, most results in this paper apply to the multi-branch case. Nevertheless, at the end of this section we briefly discuss the consequences of relaxing this assumption.

We assume that there are $N$ banks located symmetrically around a circle of measure 1. There is an entrepreneur population uniformly distributed around the circle. Each entrepreneur has an indivisible investment project that requires a capital inflow of $\$ 1$, and she has no private source of funds, so that she has to look for a loan of $\$ 1$. When contracting a loan, entrepreneurs consider the interest rate that they have to pay, and the per length "transportation cost", $\tau$, that they have to sustain to "reach" the chosen bank.

We assume that banks live forever, while borrowers live two periods (OLG). ${ }^{12}$ Thus in each period, the market for loans consists of new and old borrowers. We consider the general case of a growing economy where the borrower population increases at a rate $\lambda$. Then, in any period, the ratio between new and old borrowers will be $1+\lambda$. It is worth to specify that with "new" borrowers we mean entrepreneurs that are applying for credit for the first time. Not necessarily this needs to have to do with age. New borrowers could be, for example, firms that previously auto-financed their operations, or entrepreneurs that just moved in the area. The symmetric argument can be applied to borrowers that die and leave the market.

Borrowers are heterogeneous in their credit-worthiness. Each generation consists of a share $\theta$ of "good" entrepreneurs and a share $1-\theta$ of "bad" entrepreneurs. "Bad" entrepreneurs repay the loan with probability zero, so that the bank's expected value of a loan to a bad entrepreneur is zero, regardless of the interest rate. ${ }^{13}$ "Good" entrepreneurs repay the

${ }^{11} \mathrm{~A}$ number of papers modelling strategic interaction in the banking industry consider Cournot competition (see Hannan, 1991, Montgomery, 1991, and Dietsch, 1992) or Bertrand competition (see Dell'Ariccia et al. 1997, and Yannelle, 1995). However, for our purposes this two models are inadequate. On the one hand, Cournot competition implicitly assumes homogeneous consumers, making it difficult to introduce asymmetric information in the analysis. On the other hand, Bertrand competition has the disadvantage of making the demand function at the bank level infinitely price elastic, leading to interesting, but rather extreme results.

${ }^{12}$ This assumption simplifies the analysis. It would be interesting to generalize the model to the case of firms potentially living forever, with a probability of death. Our intuition is that the main results would hold.

${ }^{13}$ This hypothesis can be relaxed. As long as the expected value of lending to the bad type is negative, the main results hold. 
loan with probability one, thus banks will receive the payment $r$ equal to $1+R$, where $R$ is the interest rate.

We assume that there is some form of "learning by lending". Through the lenderborrower relationship, banks are able to acquire some of their clients private information, that they can exploit in subsequent periods. We assume that this information is proprietary to the lending bank. ${ }^{14}$ Consequently, banks have an advantage against each other, with respect to borrowers with whom they have previously established a lending relationship. More formally, we assume that the type distribution of new potential borrowers is public information, while the type of any individual borrower remains unknown until the end of its first period. Hence, this information is revealed to the bank and the entrepreneur only after the loan has been granted and invested. At that point, both the entrepreneur and the financing bank learn the entrepreneur's type. ${ }^{15}$ However, banks do not learn the type and "age" of their competitors' customers. Hence, in any period, banks know type and age only of those borrowers who were their clients in the previous period. This assumption wants to capture the idea that a lender acquires a deeper knowledge than its competitors regard its own costumers. ${ }^{16}$ The point is that not all the information can be summarized in the borrower's credit history (generally publicly available): for example, the lender may learn additional information by monitoring the borrower's activity or having access to its books.

We assume that banks face a constant cost for funds. In other words, we consider a situation where each bank has access to an unlimited quantity of money market funds at cost $c$, equal to $1+C$ per period, where $C$ is the money market rate (equivalently consider the case where capacity constraints are not binding).

In each period the game has two stages. In stage one, banks compete à là Nash in the interest rate for the "free market", that is new borrowers and old "bad" borrowers rejected by competitor banks. In stage two, banks offer their old good clients a rate to keep them from switching to the competition. Entrepreneurs move last, each of them choosing the best offer in terms of interest rate and "transportation cost". This time setup is the same as in Greenwald (1986), and Dell'Ariccia et al. (1997). It is meant to capture the idea that market rates are public knowledge, and that banks' ability to extract surplus from creditworthy clients is

${ }^{14}$ See Pagano and Japelli (1993) for a similar learning structure.

${ }^{15}$ For simplicity I assume that at the end of each period banks learn also the position of the firms to which they lend money.

${ }^{16}$ This assumption seems very strong. In the real world banks have often easy access to the credit history of applicants. Nonetheless, as long as it is costly for banks to screen new projects, the main results of this paper do not change qualitatively (see Appendix). We can also imagine that even if banks can distinguish new firms from old ones, they still do not know if old firms are applying because rejected by their previous bank or because they are dissatisfied with its service. 
limited. The point is that good borrowers have always the option to leave and borrow from a competitor bank at the market rate, whenever their bank does not offer sufficiently convenient conditions.

\section{A. Short Run Equilibrium}

In this section we characterize the equilibrium for the market depicted above when there is an exogenously fixed number of competitor banks, $N$. We restrict the analysis to symmetric Nash equilibria in location and interest rate, and to Markov strategies. ${ }^{17}$

To solve this game we use backward induction. First, consider stage two. Each bank observes the realization of stage one, and maximizes the profits on its own creditworthy borrowers, regardless of the rate it offered in stage one. Creditworthy borrowers find themselves locked in a bank-client relation+ship being unable to signal their quality to competitor banks. Hence, the only limit on the bank's ability to extract surplus from these borrowers is represented by the market rate chosen by competitor banks in stage one. Let $R_{\text {old }}$ be the interest rate that bank $i$ charges on "good" borrowers, and $R_{m}$ the market rate (from stage one) that bank $i^{\prime} s$ neighbor banks $(i-1, i+1)$ charge to new borrowers. Because creditworthy entrepreneurs are riskless, as long as $R_{m}>C$, it is profitable for bank $i$ to offer them an interest rate that will keep them from leaving. We then have the following result:

claim 1 (1) Bank $i$ will charge its old "good" borrowers located at $x$ a rate $\widehat{R}_{\text {old }}(x)=$ $R_{m}+r\left(\frac{1}{N}-2 x\right)$. (2) Bank $i$ will deny credit to all its old "bad" borrowers.

Claim 1 holds for two reasons. First, $\widehat{R}_{\text {old }}($.$) represents a limit price for "good"$ borrowers, or the highest interest rate that bank $i$ can charge without losing creditworthy clients to the competition. Second, the expected value of lending to "bad" entrepreneurs is zero. $\widehat{R}_{\text {old }}($.$) derives directly from the indifference condition between bank i$ and bank $i+1$ for an old "good" client of bank $i$, located at distance $x \in\left[0, \frac{1}{N}\right]$ from bank $i$. That condition is

$$
r_{\text {old }}+\tau x=r_{m}+\tau\left(\frac{1}{N}-x\right)
$$

where $r_{\text {old }}=1+R_{\text {old }}, r_{m}=1+R_{m}$, and $\tau$ is the "transportation cost" for the borrowers.

${ }^{17}$ The analysis of "collusive" equilibria should be the next step in the research agenda. 
Using claim 1, that characterizes the equilibrium of the sub-game, and normalizing the mass of old borrowers in the economy to be $\frac{\theta}{2}$, we can write bank $i^{\prime} s$ profits from old good customers as

$$
\begin{aligned}
\Pi_{\text {old }}^{t}\left(r_{m}, N, c\right) & =\theta \int_{0}^{\frac{s_{t-1}}{2}}\left[\left(r_{m}-c\right)+\tau\left(\frac{1}{N}-2 \zeta\right)\right] d \zeta \\
& =\theta\left\{\frac{s_{t-1}}{2}\left[\left(r_{m}-c\right)+\frac{\tau}{N}\right]-\tau\left(\frac{s_{t-1}}{2}\right)^{2}\right\}
\end{aligned}
$$

where $s_{t-1}$ is the market share of bank $i$ in period $t-1$. As expected the profit from known creditworthy customers is increasing with the degree of product differentiation: banks' market power increases with the "transportation cost". As in standard models $\Pi_{\text {old }}^{t}\left(r_{m}, N, c\right)$ is decreasing with the number of banks in the market and the cost of funds, $c$.

Now we can solve stage one. In stage one, in each period $t$, banks maximize the sum of the profits they make in $t$ on the "free market", consisting of unknown borrowers (e.g. new entrepreneurs and old entrepreneurs rejected by their competitors), and the discounted total profit in period $t+1$. Because of asymmetric information, profits in $t+1$ depend on the bank's market share in $t$, and thus on the interest rate that the bank charges to unknown borrowers in $t$. In other words, the larger the market share in period $t$, the larger the number of borrowers whose type the bank knows in $t+1$. The bank objective function reads as

$$
\max _{r^{t}}\left\{\Pi_{\text {free }}^{t}\left(r^{t}, r_{o}^{t}, s^{t-1}, N\right)+\delta\left[\Pi_{\text {free }}^{t+1}\left(r^{t+1}, r_{o}^{t+1}, s^{t}, N\right)+\Pi_{o l d}^{t+1}\left(r_{m}^{t+1}, N, s^{t}\right)\right]\right\}
$$

where $r_{o}$ is the gross interest rate offered by the bank's closest competitors. To write Eq.(3) in an explicit form we need to derive the loan demand function at the bank level. A new firm located at a distance $x \in\left[0, \frac{1}{N}\right]$ from bank $i$ is indifferent between $i$ and its neighbors if $^{18}$

$$
\theta r_{i}+\tau x+\delta\left[\theta E\left(r_{o}^{t+1}\right)+\tau\left(\frac{1}{N}-x\right)\right]=\theta r_{o}+\tau\left(\frac{1}{N}-x\right)+\delta\left[\theta E\left(r_{i}^{t+1}\right)+\tau x\right]
$$

notice that the payment has to be multiplied by $\theta$ because new firms do not know their type. ${ }^{19}$ The discounted terms represent the cost of borrowing in the second period conditionally on being a "good" or a "bad" type, given the banks" strategy for loans to old customers. Solving for $x$ and multiplying by two we get market share of bank $i$ as a function of $N, r_{i}$, and $r_{o}$, that is

$$
s_{t}\left(r_{i}, r_{o}, N\right)=\frac{\left(r_{o}-r\right)-\delta \cdot\left(E\left(r_{o}^{t+1}\right)-E\left(r^{t+1}\right)\right)}{\frac{\tau}{\theta} \cdot(1-\delta)}+\frac{1}{N}
$$

\footnotetext{
${ }^{18}$ To get Eq.(4) we just need to simplify this expression:

$$
\theta r_{i}+\tau x+\delta\left[\theta\left(E\left(r_{o}^{t+1}\right)+\tau\left(\frac{1}{N}-x\right)\right)+(1-\theta) \tau\left(\frac{1}{N}-x\right)\right]
$$$$
=\theta r_{o}+\tau\left(\frac{1}{N}-x\right)+\delta\left[\theta\left(E\left(r_{i}^{t+1}\right)+\tau x\right)+(1-\theta) \tau x\right]
$$

${ }^{19}$ The expected payment to the bank is $\theta r$. This effect reminds the classical result in Stiglitz and Weiss (1981) where riskier firms are more willing to pay high interest rates. 
The indifference condition between bank $i$ and bank $i+2$ for an old bad firm located at a distance $y \in\left[0, \frac{2}{N}\right]$ from bank $i$ is

$$
\tau y=\tau\left(\frac{2}{N}-y\right)
$$

This follows from the assumption that banks learn the type of their customer. Then old bad firms cannot borrow from the bank that initially financed their project, and the two closest "available" banks are $2 / N$ apart. The payment term does not appear in Eq.(6) because bad firms know that they are not going to pay back the loan. In other words, bad firms care only about the distance from the bank that they choose to use. Considering that bank $i$ knows its own old clients, from Eq.(6) we get its share of old bad firms

$$
b_{i}^{t}=2 y\left(r_{i}, r_{o}, N\right)-s_{i}^{t-1}=\frac{2}{N}-s_{i}^{t-1}
$$

where $s_{i}^{t-1}$ is the market share of bank $i$ in period $t-1$. If we multiply Eq.(2), Eq.(5), and Eq.(7) by the mass of their respective category of borrowers, and plug them in Eq.(3), we obtain the objective function for bank $i$. Now we can state the following result:

Lemma 1 The short-run symmetric Nash equilibrium gross interest rate for this game is

$$
\hat{r}=\frac{\frac{\tau}{\theta}(1-\delta)}{N(1+\delta)}+\frac{c(1+\delta \theta-\delta(1-\theta))}{\theta(1+\delta)}
$$

\section{Proof. See Appendix.}

The equilibrium gross rate $\hat{r}$ is decreasing with the percentage of good firms, ${ }^{20}$ and with the number of banks in the market, while it increases with the degree of product differentiation $\tau$ and the money-market gross rate $c$. Any change in the money-market interest rate is more than fully passed through on the loan interest rate. Banks have to compensate for the higher losses that they suffer from "bad" borrowers when the cost of funds increases. The equilibrium rate is decreasing in $\delta$. A lower discount rate induces banks to compete more aggressively for client firms, because a larger market share today means larger profits tomorrow. $^{21}$ Hence, when future profits become relatively more important, the level of the present interest rate decreases. Notice that with $\delta=1$ (no discounting) banks charge the

${ }^{20}$ We can write the derivative of the equilibrium interest rate with respect to the share of "good" borrowers in the market as

$$
\frac{\partial \hat{r}}{\partial \theta}=\frac{-\frac{\tau}{\theta^{2}}(1-\delta)}{N(1+\delta)}+c\left[\frac{-(1-\delta)}{\theta^{2}(1+\delta)}\right]<0
$$

${ }^{21}$ The derivative of the equilibrium interest rate with respect to $\delta$ reads

$$
\frac{\partial \hat{r}}{\partial \delta}=-\frac{\tau}{\theta N(1+\delta)}-\frac{\tau}{\theta} \frac{1-\delta}{N(1+\delta)^{2}}-2 c \frac{1-\theta}{\theta(1+\delta)^{2}}<0
$$


money market rate $C$, and the gross rate becomes equal to $c$ attaining the Bertrand competition result. This result depends on the assumption that banks learn the position of their customers. Then the higher transportation cost sustained by firms choosing the farthest bank in the first period is exactly matched by a lower rate paid to that bank in the second period. The intuition for this effect is that in the second period a good old firm is the more "captive" the farther it is from the closest competitor bank. Finally, a very convenient feature of this result is that $\widehat{r}$ does not depend on the size of the borrowers population, but only on its composition. That also means that $\widehat{r}$ does not depend on the rate of growth of the population. ${ }^{22}$

We can now compute the various components of the bank's profits. Consider any period $s$, and normalize the entrepreneur population, so that there is a mass $\frac{1}{2}$ of old borrowers, and consequently a mass $\frac{1+\lambda}{2}$ of new borrowers in the economy. Then we can write the bank's equilibrium profit for period $s$, for the case with $N$ symmetric banks (each with $\frac{1}{N}$ market share) in the market

$$
\Pi_{\text {old }}^{1 / N}(s)+\Pi_{\text {free }}^{1 / N}(s)=\frac{\tau(1-\delta)(2+\lambda)}{2 N^{2}(1+\delta)}-\frac{2 c(1-\theta)(2+\lambda) \delta}{N(1+\delta)}+\frac{\tau \theta}{4 N^{2}}
$$

From Eq.(9) we can see that profits are decreasing in the number of banks, $N$, and the cost of funds, $c$, and increasing in $\tau$. An interesting result is that profits are decreasing in $\delta .^{23}$ The intuition behind this result is straightforward, and follows from the effect of $\delta$ on the equilibrium interest rate. $\delta$ is the inverse of the discount rate, the lower the discount rate (the larger $\delta$ ), the larger the effect of asymmetric information on competitive behavior. If banks care only about the present, they do not consider the informational effects of their pricing strategy, thus they compete less aggressively for new clients. In other words, the lower $\delta$, the less important is to acquire a large market share, and the result is a higher equilibrium interest rate. The extreme case when $\delta=0$, "future does not matter", represents an upper bound for the "free market" interest rate. Another not surprising, but important result is that the presence of "bad" borrowers hurts both banks and creditworthy entrepreneurs. In the short-run equilibrium, to a lower $\theta$ correspond lower banks' profits and higher interest rates for both the free market and old "good" borrowers. Creditworthy entrepreneurs pay for their inability to distinguish themselves from the bad ones. Banks pay their inability to screen bad from good among untested entrepreneurs.

${ }^{22}$ This result is not particularly surprising. In the standard Salop's model, the equilibrium price does not change if the density of consumers on the circle changes.

${ }^{23}$ The derivative of the per period profits with respect to $\delta$ is:

$$
\frac{\partial\left(\Pi_{\text {old }}^{1 / N}+\Pi_{\text {free }}^{1 / N}\right)}{\partial \delta}=-2 \frac{(2+\lambda)[\tau+c(1-\theta) N]}{N^{2}(1+\delta)^{2}}<0
$$




\section{B. Steady State Market Structure}

Until now we assumed the number of banks on the market to be exogenous. In this section we extend the analysis to the long run and treat the number of banks as endogenous. We can model the bank's entry/exit problem as an option. In any period $t$ a potential entrant has the option to enter the market, or to wait until the next period. Similarly, an active bank has to decide whether to stay on the market, or to exit. A steady state equilibrium will be one where the number of banks on the market is such that no entry or exit occurs.

In this model banks sustain an informational sunk cost to enter the market. In other words, banks have to accept to make some losses on "bad" loans in the entry period, in order to gather the information that enables them to exploit their creditworthy clients in the subsequent periods. This means that in this model to be on the market is valuable by itself, thus we expect: $\bar{N}_{n o-e n t r y} \leq \bar{N}_{n o-e x i t}$.

Standard models of competition on the circle assume that competitors relocate if entry occurs, imposing a symmetric industry structure and maximum differentiation. Here as there the focus is on the extent of entry and this assumption makes the model more tractable. ${ }^{24}$ However, for our case some preliminary considerations are required. A first point is that in our model to change location is costly. Banks acquire information about borrowers in their "area". Consequently, to change location disrupts banks' "informational capital", reducing their profits. It is clear from Eq. (1) that, moving away from the center of the segment of "known" borrowers, a bank has to lower the interest rate charged to its old creditworthy clients. Moreover, to move, implying a smaller share of known borrowers, will also increase the number of "bad" entrepreneurs whom the bank will finance on the "free market". A second point is that the profits of an entrant are lower if incumbents do not relocate, or relocate only partially. We then have the following result:

claim 2 : The no-entry number of banks under the assumption of "free relocation" (equidistant banks) is larger than it would be considering relocation costs: $N_{\text {no-entry }}^{\text {true }} \leq N_{\text {no-entry }}^{\text {equid }}$.

Claim 2 implies that any result of blockaded or deterred entry obtained under the assumption of equidistant banks, will hold under assumptions taking into account the "true" banks' relocation behavior. In other words, assuming equidistant banks, we are making entry "easier". Hence, if we could show that asymmetric information generates a barrier to entry with equidistant banks, we would obtain a more general result. To do so, we define $\Pi_{\text {free }}^{0}(s)$ the profit on the "free market" for a new entrant, when the borrower population is normalized as for Eq.(9). Then we prove the following lemma.

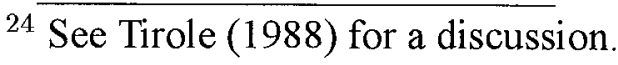


Lemma 2 In any period $t>s$, the equilibrium per period profit, $\Pi_{\text {old }}^{1 / N}(t)+\Pi_{\text {free }}^{1 / N}(t)$, will be equal to $(1+\lambda)^{t-s}\left[\Pi_{\text {old }}^{1 / N}(s)+\Pi_{\text {free }}^{1 / N}(s)\right]$, and $\Pi_{\text {free }}^{0}(t)=(1+\lambda)^{t-s} \Pi_{\text {free }}^{0}(t)$.

Proof. See Appendix.

We then are able to prove the following important proposition:

Proposition 1 Under the assumptions: ( $i$ ) zero exogenous fixed cost, (ii) equidistant banks, and (iii) $1+\lambda<\frac{1}{\delta}$, any steady state market structure will be characterized by a finite number of banks, $N$, such that

$$
\frac{\tau(1+\lambda)[2(1-\delta)+\theta \delta]}{4 c(1-\theta)}<N<\frac{\tau(1+\lambda)[2(1-\delta)+\theta \delta]}{2 c[1+\delta(1+\lambda)](1-\theta)}
$$

Proof. By Lemma 2, in any period $t$, we can write the no-entry condition as ${ }^{25}$

$$
\Pi_{\text {free }}^{0}(s)+\frac{\delta(1+\lambda)}{1-\delta(1+\lambda)}\left(\Pi_{\text {old }}^{1 / N}(s)+\Pi_{\text {free }}^{1 / N}(s)\right) \leq 0
$$

Assumption (iii) guarantees that Eq.(10) is a meaningful expression. It is basically assuming that the rate of growth of the borrower population has to be lower that the discount rate. ${ }^{26}$ With the assumption of symmetric location, the first order conditions for the entrant are the same as for the incumbent banks (indeed the f.o.c. do not depend on period $t-1$ market shares). ${ }^{27}$ That is: $\hat{r}$ is the same as in Eq.(8). Thus for an entrant with $s^{t-1}=0$ we have

$$
\Pi_{\text {free }}^{0}(s)=\frac{\tau(1-\delta)(1+\lambda)}{2 N^{2}(1+\delta)}-\frac{c(1-\theta)(1+2 \delta+\delta \lambda)}{N(1+\delta)}
$$

and plugging Eq.(9) and Eq.(11) in Eq.(10) we get

$$
\bar{N}_{n o-e n t r y}=\frac{\tau(1+\lambda)[2(1-\delta)+\theta \delta]}{4 c(1-\theta)}
$$

The second threshold is given by the no-exit condition. In each period it has to be profitable for incumbent banks to compete for the "free market". If in period $t$ a bank does not compete for new borrowers, in period $t+1$ it will be out of the market (given firms live only two

${ }^{25}$ This is equivalent to: $\Pi_{\text {free }}^{0}+\delta V_{\text {in }} \leq \delta V_{\text {out }}$, where $V_{\text {in }}$ and $V_{\text {out }}$ represent the value of being in and out. See Appendix.

${ }^{26}$ We can derive the discount rate from: $\delta=\frac{1}{1-\rho}$, then we can rewrite $(i i i)$ as: $\lambda<\rho$.

${ }^{27}$ This is because the number of old firms that each bank gets in each period does not depend on the interest rate the bank charges to the free market in that period, but only on its market share in the previous one. 
periods). Thus banks have to find more profitable to serve both new and old borrowers than to lend solely to their own creditworthy clients. We then can write the no-exit condition as ${ }^{28}$

$$
\Pi_{\text {free }}^{1 / N}(s)+\delta(1+\lambda) \Pi_{\text {old }}^{1 / N}(s) \geq 0
$$

and the solution reads

$$
\bar{N}_{n o-e x i t}=\frac{\tau(1+\lambda)[2(1-\delta)+\theta \delta]}{2 c[1+\delta(1+\lambda)](1-\theta)}
$$

that for $\delta(1+\lambda)<1$ is larger than $\bar{N}_{\text {no-exit. q.d.e. }}$

Proposition 1 shows that the solution from the previous section is still an equilibrium when we allow for entry-exit, if and only if

$$
\bar{N}_{n o-e n t r y} \leq N \leq \bar{N}_{n o-e x i t}
$$

This is the first important and non standard result of this paper. Notice that we have assumed zero "external" fixed costs. It is asymmetric information that determines a limit to the number of banks that the market can sustain in equilibrium. In this market, even without an exogenous fixed cost, only a finite number of banks can make non negative profits. In standard models of horizontal differentiation the equilibrium number of competitors is determined by an exogenous fixed cost (Salop, 1979). In those models, with zero fixed costs, the only long-run equilibrium is characterized by an infinite number of competitors. ${ }^{29}$ Here the adverse selection effect stemming from the informational asymmetries between incumbents and entrants generates an endogenous fixed cost. ${ }^{30}$ Moreover, in a sequential entry setting this fixed cost would represent a first mover advantage, to the extent that early entrants would suffer from adverse selection less than late entrants. We then can say that asymmetric information represents a barrier to entry in the banking industry. The intuition for this result is that increasing the number of banks competing on the market, the equilibrium interest rate decreases, while the relative composition of good and bad clients in banks' portfolios does not change (each bank always gets one $N$ th of both types). The incentive for banks to enter the market is provided by the hope to earn future informational rents. New competitors will enter the market and fight for a share of the "free market" as long as today losses on non-creditworthy clients will be lower than discounted future profits from creditworthy ones. Then, for $N$ large enough, discounted future profits become smaller than present losses and no new bank, will have an incentive to enter. Notice that it is asymmetric information and not "risk" to generate this result. It is easy to show that in the presence of homogeneous borrowers, with a probability of success, $\theta \in(0,1)$, this market behaves as a standard Salop's model.

${ }^{28}$ That is equivalent to $\Pi_{\text {old }}^{1 / N}+\Pi_{\text {free }}^{1 / N}+\delta V_{\text {in }} \geq \Pi_{\text {old }}^{1 / N}+\delta V_{\text {out }}$. See Appendix.

${ }^{29}$ See Sutton (1991).

${ }^{30}$ We might also interpret $\bar{N}_{n o-e n t r y}$ and $\bar{N}_{n o-e x i t}$ as an upper bound for the no-entry/no-exit band in models with a positive exogenous fixed costs and asymmetric information. 
From Proposition 1 we are able to derive a second important result.

Proposition 2 As long as $1+\lambda<\frac{1}{\delta}$, markets characterized by a higher growth rate of the borrower population can sustain a larger number of banks in equilibrium.

\section{Proof. Standard.}

The no-entry and no-exit thresholds are increasing functions of the borrower population growth rate, $\lambda .{ }^{31}$ The implication of this result is that informational barriers to entry are lower in economies that grow faster. Because of asymmetric information and learning by lending, incumbent banks have an advantage with respect to borrowers with whom they have already established a lending relationship. As $\lambda$ rises, the proportion of such borrowers in the economy decreases. Consequently, with a higher $\lambda$, potential entrants face less severe adverse selection problems, and find entry easier. It is worth to notice that it is the composition and not the absolute size of the market that matters. The equilibrium number of banks does not depend on the size of the market defined as the mass of borrowers around the circle. With zero fixed costs, if we double the density of borrowers without changing their age and type composition the equilibrium does not change. What matters is the relative weight of bad/good, and new/old entrepreneurs in the economy. As expected $\bar{N}_{n o-e n t r y}$ goes to infinity as $\theta$ goes to 1 , that is as the market approaches a standard market without asymmetric information. $\bar{N}_{\text {no-entry }}$ increases with market differentiation $\tau$ (because banks can make more profit from good firms), and it decreases with $c$ and the discount rate for the same reasons discussed before. When the discount rate increases, the future counts less, thus competition becomes less fierce and profits increase.

Notice that the Nash equilibrium characterized in this paragraph is not always sub-game perfect. In other words, for some industry structures a one period deviation might be profitable. However, we can prove the following result

Lemma 3 For any $\delta$ and $\lambda \mid 1+\lambda<\frac{1}{\delta}$, for $N=\bar{N}_{\text {no-entry }}$ the proposed Nash equilibrium is also sub-game perfect.

Proof. See Appendix.

31 The partial derivatives are:

$$
\begin{aligned}
\frac{\partial \bar{N}_{n o-e n t r y}}{\partial} & =\frac{\tau(2(1-\delta)+\theta \delta)}{4 c(1-\theta)}>\mathbf{0} \\
\frac{\partial \bar{N}_{n o-e x i t}}{\partial \lambda} & =\frac{2 c \tau(1-\theta)(2(1-\delta)+\theta \delta)}{[2 c(1+\delta(1+\lambda))(1-\theta)]^{2}}>\mathbf{0}
\end{aligned}
$$

with $\delta(1+\lambda)<1$. 
Finally, a brief comment on multi-branch competition. In this setup, as long as there are at least two banks in the market, all borrowers are financed. Hence, the industry structure generates an inefficiency to the extent that bad borrowers always find financing in their second period. On the contrary, in a monopoly no information would be "lost" and no old bad entrepreneur would be financed. Thus, if we relaxed the assumption that rules out cartels and multi-branch banking, there would be an incentive for banks to merge to reduce information losses. Moreover, in the absence of exogenously imposed fixed costs, the incumbent banks and potential entrants would set the number of branches to infinite. Hence, our setup would collapse to a game where banks compete in a Bertrand fashion over the interest rate. We do not develop that case here. However, it is worth noticing that our main result of deterred entry holds in that setting. ${ }^{32}$

\section{Discussion and Policy Implications}

To the broadest definition an economic barrier to entry is some characteristic of the demand or the cost structure that gives incumbents an advantage over potential entrants. In the previous section we have showed that adverse selection generates an endogenous sunk cost that protects incumbent banks from the competition of new financial institutions. The structure of the industry forces new entrants to make the equivalent of a minimum investment in information, which entails a fixed and sunk cost of entry. As a consequence, the steady-state equilibrium is characterized by a finite number of competing lenders, even in the absence of exogenous fixed costs. To this extent asymmetric information represents an important determinant of the market structure of the banking industry. However, adverse selection effects are not the only factor that limits the amount of competition in the credit industry. Other technological, informational, and institutional factors contribute to reduce the number of competitors in loan markets, and to make the banking industry "not contestable". ${ }^{33} \mathrm{~A}$ second simplification of our model is that it does not include the deposits side of the market. We concentrate on loan markets, and limit the analysis to the "output side" of banks' activity. Nevertheless, our model provides some important insights on the interaction among financial intermediaries, and it has some relevant implication for the debate about regulation in banking.

If significant economic barriers to entry exist, the removal of legal barriers will not necessarily increase competition. Then, regulatory reforms aimed to promote competition, like the liberalization of cross-border banking activities in Europe, will be more effective on

${ }_{32}$ Dell'Ariccia, Friedman, and Marquez (1997) analyze a mono-period Bertrand setup and show that the only equilibrium industry structure is a duopoly with blockaded entry.

${ }^{33} \mathrm{~A}$ substantial literature has identified a number of factors that contribute to limit competition in the banking industry, among them: fixed costs to establish a network, reputation effects, depositors' switching costs, and minimum capital requirements. See, Vives (1991), Dermine (1991) and Dietsch (1992) for a discussion of contestability in banking. 
those segments of the market characterized by lower economic barriers. From this point of view, our model has two strong implications. First, new entry will be more difficult in markets where incumbent banks have been able to acquire very pervasive information about their customers. Second, new entry will be more difficult in those segments of the credit markets where asymmetric information is more important. ${ }^{34}$ Banks operating in systems that allow them to establish close links with their client firms will be able to absolve their monitoring and screening functions more efficiently. However, our model suggests that in such regulatory frameworks there will also be higher barriers to entry, and less competition. ${ }^{35}$ Then, a trade-off between efficiency and competition emerges. At one end, "universal bank" systems (German style) characterized by higher barriers to entry, and by more effective screening and monitoring activity. At the other end, "market based" systems (US style) more open to new competitors, but less effective in discriminating the projects to finance from the ones to reject. ${ }^{36}$

Different degrees of competition may prevail on different segments of the market, even within the same regulatory environment. Typically, borrowers may be characterized by different degrees of asymmetric information. For example, it may be that the agents' ability to signal their quality differs by their size, or the industry in which they are operating. On the one hand, there may be economies of scale in acquiring information about individual firms, so that lending to small firms involves a higher information cost per dollar borrowed. On the other hand, there may be activities for which credit-worthiness evaluation is easier, and industries where borrowers are able to provide more collateral and guarantees, diminishing the importance of the informational asymmetry. Then, borrowers operating in segments characterized by a lower degree of asymmetric information will be the main beneficiaries of regulatory reforms aimed to increase competition in credit markets. The main implication of this analysis is that a deregulation of the banking industry might have distributional effects, not only between lenders and borrowers, but also among different categories of borrowers. In particular, borrowers characterized by higher degrees of asymmetric information might find themselves in a worse position than before the deregulation. ${ }^{37}$ The idea is that the increased

${ }^{34}$ With regard to this, the evolution of the European banking markets has been consistent with the predictions of our model. In the wake of the removal of legal barriers to entry retail banking markets (characterized by relevant informational asymmetries) have remained concentrated and dominated by domestic banks. Financial institutions have limited their cross-border activities to wholesale banking, where the "informational costs" per dollar lent are probably lower. See Hoschka (1993), and Gual and Neven (1992).

${ }^{35}$ Steinherr and Huveneers (1994) find that the market share of foreign banks is significantly lower in "universal bank" countries.

${ }^{36}$ For a general discussion of the welfare implication of different financial systems see Allen and Gale (1995).

${ }^{37}$ For example small firms for which the informational cost per unit of loan might be higher, and firms operating in segments where the skills and the reputation of the owner/manager are often the more relevant asset. 
competition on the segments of the market where private information is not an important factor may distract funds from the segments where informational asymmetries are relevant. In the wake of financial deregulation, the supply of loans for those segments where the reform has effectively promoted competition will increase. If the supply of funds to the banking system is upward sloping, this will imply an increase of banks' marginal and average cost. ${ }^{38}$ Then, for sectors where the regulatory reform has been less effective, the positive impact of an increased competition could be overwhelmed by this cross-segment effect. ${ }^{39}$ The final result would depend on the various elasticities and the relative importance of the different sectors. ${ }^{40}$

The analysis of the merger activity in the banking industry goes beyond the scope of this paper. However, our model hints to some explanations for the wave of mergers and acquisitions that occurred both in the US and Europe in the last few years. In particular, the analysis in this paper provides a rationale for "out of market" mergers and acquisitions. As those that dominated the evolution of cross-border banking activity in Europe, where foreign entry occurred mainly through the purchase of a domestic bank. In our view, banks entering new markets use mergers and acquisitions to circumvent the informational barriers discussed above. In other words, the acquisition involves the appropriation of both physical and informational capital. By buying an existing bank, the entrant is able to acquire the specific and private information that the acquired bank possesses about its clients. Hence, the entrant is able to avoid the adverse selection problem described in our model.

Finally, we have to address the issue of information sharing. Pagano and Jappelli (1993) show that information sharing may emerge endogenously as a solution to asymmetric information problems. There are a number of features of our model that would change if banks shared the information that they acquire about their clients. Summarizing, the effect of information sharing would be threefold. First, competition for borrowers that have proven themselves creditworthy would increase. Second, competition for new borrowers would decrease, as the gain of market shares loses its informational role. Third, informational barriers to entry would fall, leading to a more competitive banking industry. The incentive to share information would depend on the net result of these three effects on banks profits. In the context of our model information sharing leads to a perfectly competitive enviroment, and a zero profit solution. Hence, banks never have an incentive to exchange information. In more complex models where borrowers act strategically and where moral hazard problems may

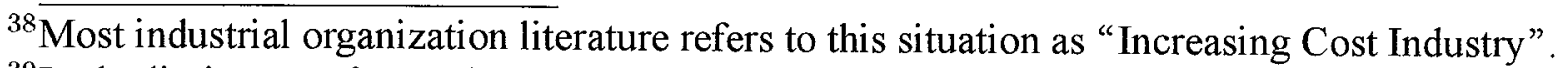

${ }^{39}$ In the limit case of a market segment where the deregulation was completely ineffective, borrowers would only experience the "cross-segment" effect, and would surely pay higher interest rates than before the regulatory reform.

${ }^{40}$ With regard to this, Berger, Kashyap and Scalise (1995) find some evidence of a reduced supply of funds to small business after the deregulation in the US. For a more detailed analysis of the distributional aspects of this model see the author's Ph.D thesis (MIT 1997). 
arise, information sharing may emerge as a market solution. ${ }^{41}$ However, that analysis goes beyond the scope of this paper.

\section{Conclusions}

In this paper we showed that asymmetric information and learning in the banking industry generate adverse selection effects that represent a barrier to entry for new lending institutions. In that context we also showed that entry will be easier in more dynamic markets, where the borrower population grows at a higher rate. We limited this study to the banking industry, but the framework in this paper and its implication could be easily adapted to analyze other industries characterized by important informational asymmetries like, for example, the market of insurance companies, or HMOs.

There are some points that are worth considering for future research. The analysis in this paper suggests that there is a bilateral interaction between the structure of the banking industry and the structure of the markets where firms asking for financing operate. In this paper I assumed a particular structure for the firms and derived a market structure for the credit industry. It would be interesting to integrate the model with the analysis of how the competitive environment in which firms operate is affected by the structure of the banking industry.

${ }^{41}$ Pagano and Padilla (1997) show that by sharing information, financial institutions can pre-commit not to extract "too much" surplus form creditworthy borrowers in future periods, and reduce moral hazard problems. 


\section{DERIVATION OF THE EQUILIBRIUM INTEREST RATE}

We consider the case where the borrower population is growing at rate $\lambda$. Take any period $t$, and normalize the entrepreneur population, so that there is a mass $\frac{1}{2}$ of old borrowers, and consequently a mass $\frac{1+\lambda}{2}$ of new borrowers in the economy.

Lemma 1 The short-run symmetric Nash equilibrium gross interest rate for this game is

$$
\hat{r}=\frac{\frac{\tau}{\theta}(1-\delta)}{N(1+\delta)}+\frac{c(1+\delta \theta-\delta(1-\theta))}{\theta(1+\delta)}
$$

Proof. See The bank's objective function is

$$
\max _{r^{t}} \Pi_{\text {free }}^{t}\left(r^{t}, r_{o}^{t}, s^{t-1}, N\right)+\delta\left[\Pi_{\text {free }}^{t+1}\left(r^{t+1}, r_{o}^{t+1}, s^{t}, N\right)+\Pi_{o l d}^{t+1}\left(r_{m}^{t+1}, N, s^{t}\right)\right]
$$

and plugging Eq.(2), Eq.(5), and Eq.(7) in Eq.(3), we get

$$
\begin{aligned}
& \max _{r}(r \theta-c)\left(\theta \cdot \frac{\left(r_{o}-r\right)-\delta \cdot\left(E\left(r_{o}^{t+1}\right)-E\left(r^{t+1}\right)\right)}{\tau \cdot(1-\delta)}+\frac{1}{N}\right) \frac{1+\lambda}{2} \\
& -\frac{c(1-\theta)}{2}\left(\frac{2}{N}-s_{i}^{t-1}\right) \\
& +\delta \frac{(1+\lambda)^{2}}{2}\left[\left(r^{t+1} \theta-c\right)\left(\theta \cdot \frac{\left(r_{o}^{t+1}-r^{t+1}\right)-\delta \cdot\left(E\left(r_{o}^{t+2}\right)-E\left(r^{t+2}\right)\right)}{\tau \cdot(1-\delta)}+\frac{1}{N}\right)\right] \\
& +\delta \theta \frac{1+\lambda}{2}\left(\theta \cdot \frac{\left(r_{o}-r\right)-\delta \cdot\left(E\left(r_{o}^{t+1}\right)-E\left(r^{t+1}\right)\right)}{\tau \cdot(1-\delta)}+\frac{1}{N}\right)\left(r_{m}^{t+1}-c+\frac{\tau}{N}\right) \\
& -\delta \frac{1+\lambda}{2}\left[c(1-\theta)\left(\frac{2}{N}-\theta \cdot \frac{\left(r_{o}-r\right)-\delta \cdot\left(E\left(r_{o}^{t+1}\right)-E\left(r^{t+1}\right)\right)}{\tau \cdot(1-\delta)}+\frac{1}{N}\right)\right] \\
& -\delta \theta \tau \frac{1+\lambda}{4}\left(\theta \cdot \frac{\left(r_{o}-r\right)-\delta \cdot\left(E\left(r_{o}^{t+1}\right)-E\left(r^{t+1}\right)\right)}{\tau \cdot(1-\delta)}+\frac{1}{N}\right)^{2}
\end{aligned}
$$

deriving with respect to $r$ we get the first order conditions

The second order conditions are satisfied

$$
\begin{gathered}
\frac{\partial O F}{\partial r}=\frac{\theta}{2}\left(\frac{\theta\left(r_{o}-r\right)-\theta \delta \cdot\left(E\left(r_{o}^{t+1}\right)-E\left(r^{t+1}\right)\right)}{\tau \cdot(1-\delta)}+\frac{1}{N}\right)-\frac{(r \theta-c)}{2 \frac{\tau}{\theta}(1-\delta)}-\frac{\delta \cdot(1-\theta) c}{2 \frac{\tau}{\theta}(1-\delta)} \\
+\frac{\delta \theta}{2(1-\delta) \tau}\left[-\theta\left(r_{m}^{t+1}-c+\frac{\tau}{N}\right)\right. \\
\left.+\theta \tau\left(\frac{\theta\left(r_{o}-r\right)-\theta \delta \cdot\left(E\left(r_{o}^{t+1}\right)-E\left(r^{t+1}\right)\right)}{\tau \cdot(1-\delta)}+\frac{1}{N}\right)\right]=0
\end{gathered}
$$

$$
\frac{\partial^{2} O F}{\partial r^{2}}=-\frac{1}{2} \frac{(1+\delta) \theta^{2}}{(1-\delta) \tau}<0
$$

Then assuming that firms have rational expectations and imposing symmetry and steady state, we get the equilibrium gross interest rate that does not depend on $t$ or $\lambda$

$$
\hat{r}=\frac{(1-\delta) \tau}{N \theta(1+\delta)}+\frac{c(1-\delta+2 \delta \theta)}{\theta(1+\delta)} \quad \text { q.d.e. }
$$




\section{PROOF OF LEMMA 2}

Lemma 2 In any period $t>s$, the equilibrium per period profit, $\Pi_{\text {old }}^{1 / N}(t)+\Pi_{\text {free }}^{1 / N}(t)$, will be equal to $(1+\lambda)^{t-s}\left[\Pi_{\text {old }}^{1 / N}(s)+\Pi_{\text {free }}^{1 / N}(s)\right]$, and $\Pi_{\text {free }}^{0}(t)=(1+\lambda)^{t-s} \Pi_{\text {free }}^{0}(t)$.

Proof. The ratio between new and old borrowers is constant across periods. Also, from Proposition 1, we know that the equilibrium interest rate does not change across periods. If the population grows at a rate $\lambda$, in any period $t+s$, the mass of old and new borrowers will be equal to their respective masses in $t$ multiplied by $(1+\lambda)^{s}$. Then, for any period $t$ we can write

$$
\left[\Pi_{\text {old }}^{1 / N}(t+s)+\Pi_{\text {free }}^{1 / N}(t+s)\right]=(1+\lambda)^{s}\left[\Pi_{\text {old }}^{1 / N}(t)+\Pi_{\text {free }}^{1 / N}(t)\right]
$$

and

q.d.e.

$$
\Pi_{f r e e}^{0}(t+s)=(1+\lambda)^{s} \Pi_{f r e e}^{0}(t)
$$

From Lemma 2 descends an obvious corollary.

Corollary 1 Consider periods, where the borrowers population has been normalized to consist of a mass $\frac{1}{2}$ of old borrowers, and a mass $\frac{1+\lambda}{2}$ of new borrowers. then we can write

$$
\sum_{j=0}^{\infty} \delta^{j}\left[\Pi_{\text {old }}^{1 / N}(s+j)+\Pi_{\text {free }}^{1 / N}(s+j)\right]=\frac{1}{1-\delta(1+\lambda)}\left[\Pi_{\text {old }}^{1 / N}(s)+\Pi_{\text {free }}^{1 / N}(s)\right]
$$




\section{NO-ENTRY/NO-EXIT CONDITIONS}

Consider the value functions of being "in" or "out" the market. Lemma 2 and Corollary 1 imply that we can simply write

$$
\begin{gathered}
V_{\text {out }}=\max \left[0+\delta(1+\lambda) V_{\text {out }}, \Pi_{\text {free }}^{0}+\delta(1+\lambda) V_{\text {in }}\right] \\
V_{\text {in }}=\max \left[\delta(1+\lambda) V_{\text {out }}, \Pi_{\text {free }}^{\frac{1}{N}}+\delta(1+\lambda) V_{i n}\right]+\Pi_{\text {old }}^{\frac{1}{N}}
\end{gathered}
$$

Notice that given $\Pi_{\text {old }}^{\frac{1}{N}}>0$ and $\Pi_{\text {free }}^{\frac{1}{N}} \geq \Pi_{\text {free }}^{0}$ we have always $V_{\text {in }} \geq V_{\text {out }}$. The no-entry condition is

$$
\Pi_{\text {free }}^{0}+\delta(1+\lambda) V_{i n} \leq \delta(1+\lambda) V_{\text {out }} \Leftrightarrow \Pi_{\text {free }}^{0}+\delta(1+\lambda)\left(V_{\text {in }}-V_{\text {out }}\right) \leq 0
$$

the no-exit condition is

that is

$$
\Pi_{\text {old }}^{\frac{1}{N}}+\Pi_{\text {free }}^{\frac{1}{N}}+\delta(1+\lambda) V_{i n} \geq \Pi_{\text {old }}^{\frac{1}{N}}+\delta(1+\lambda) V_{o u t}
$$

$$
\Pi_{\text {free }}^{\frac{1}{N}}+\delta(1+\lambda)\left(V_{\text {in }}-V_{\text {out }}\right) \geq 0
$$

Proposition $2 \Pi_{\text {free }}^{0}+\delta(1+\lambda)\left(V_{\text {in }}-V_{\text {out }}\right) \leq 0$ if and only if $\Pi_{\text {free }}^{0}+\frac{\delta(1+\lambda)}{1-\delta(1+\lambda)}\left(\Pi_{\text {free }}^{\frac{1}{N}}+\Pi_{\text {old }}^{\frac{1}{N}}\right) \leq 0$

Proof. Assume that the no-exit condition is verified, that means

$$
V_{i n}=\Pi_{\text {free }}^{\frac{1}{N}}+\delta(1+\lambda) V_{i n}+\Pi_{o l d}^{\frac{1}{N}} \Rightarrow V_{i n}=\frac{1}{1-\delta(1+\lambda)}\left(\Pi_{\text {free }}^{\frac{1}{N}}+\Pi_{\text {old }}^{\frac{1}{N}}\right)
$$

if $\Pi_{\text {free }}^{0}+\delta(1+\lambda)\left(V_{\text {in }}-V_{\text {out }}\right) \leq 0$ then $V_{\text {out }}=0$, from $V_{\text {out }}$ definition, and substituting we get

$$
\Pi_{\text {free }}^{0}+\frac{\delta(1+\lambda)}{1-\delta(1+\lambda)}\left(\Pi_{\text {free }}^{\frac{1}{N}}+\Pi_{\text {old }}^{\frac{1}{N}}\right) \leq 0
$$

if $\Pi_{\text {free }}^{0}+\delta(1+\lambda)\left(V_{\text {in }}-V_{\text {out }}\right)>0$ then $V_{\text {out }}=\Pi_{\text {free }}^{0}+\delta(1+\lambda) V_{\text {in }}$, and substituting we get

$$
\Pi_{\text {free }}^{0}+\delta(1+\lambda)\left(V_{\text {in }}-\Pi_{\text {free }}^{0}-\delta(1+\lambda) V_{\text {in }}\right)>0
$$

that is

and becomes

$$
(1-\delta(1+\lambda)) \Pi_{f r e e}^{0}+(1-\delta(1+\lambda)) \delta(1+\lambda) V_{\text {in }}>0
$$

that, finally, gives us

$$
\Pi_{f r e e}^{0}+\delta(1+\lambda) V_{i n}>0
$$

$$
\Pi_{\text {free }}^{0}+\frac{\delta(1+\lambda)}{1-\delta(1+\lambda)}\left(\Pi_{\text {free }}^{\frac{1}{N}}+\Pi_{\text {old }}^{\frac{1}{N}}\right)>0
$$

assume now that the no-exit condition is not verified, then the no-entry condition is always verified, because $\Pi_{\text {free }}^{\frac{1}{N}} \geq \Pi_{f r e e}^{0}$, then $V_{\text {out }}=0$ and from no-exit violated we know that $V_{i n}=\delta(1+\lambda) V_{0}+\Pi_{\text {old }}^{\frac{1}{N}}$. Then we can rewrite the no-entry condition as $\Pi_{\text {free }}^{\frac{1}{N}}+\delta(1+\lambda) \Pi_{\text {old }}^{\frac{1}{N}} \leq 0$. From $\Pi_{\text {free }}^{\frac{1}{N}} \geq \Pi_{\text {free }}^{0}$ we have

$$
(1-\delta(1+\lambda)) \Pi_{\text {free }}^{\frac{1}{N}} \geq(1-\delta(1+\lambda)) \Pi_{\text {free }}^{0}
$$

that is equivalent to

we want to show that

$$
\begin{gathered}
\Pi_{\text {free }}^{\frac{1}{N}} \geq \Pi_{\text {free }}^{0}-\delta(1+\lambda) \Pi_{\text {free }}^{0}+\delta(1+\lambda) \Pi_{\text {free }}^{\frac{1}{N}} \\
\Pi_{\text {free }}^{0}+\frac{\delta(1+\lambda)}{1-\delta(1+\lambda)}\left(\Pi_{\text {free }}^{\frac{1}{N}}+\Pi_{\text {old }}^{\frac{1}{N}}\right) \leq 0
\end{gathered}
$$


that is the same as

$$
\Pi_{f r e e}^{0}+\frac{\delta(1+\lambda)}{1-\delta(1+\lambda)}\left(\Pi_{\text {free }}^{\frac{1}{N}}+\Pi_{\text {old }}^{\frac{1}{N}}\right) \leq 0
$$

and

$$
\Pi_{\text {free }}^{0}-\delta(1+\lambda) \Pi_{\text {free }}^{0}+\delta(1+\lambda) \Pi_{\text {free }}^{\frac{1}{N}}+\delta(1+\lambda) \Pi_{\text {old }}^{\frac{1}{N}} \leq 0
$$

then from above we know that

$$
\Pi_{\text {free }}^{0}-\delta(1+\lambda) \Pi_{\text {free }}^{0}+\delta(1+\lambda) \Pi_{\text {free }}^{\frac{1}{N}}+\delta(1+\lambda) \Pi_{\text {old }}^{\frac{1}{N}} \leq \Pi_{\text {free }}^{\frac{1}{N}}+\delta(1+\lambda) \Pi_{\text {old }}^{\frac{1}{N}} \leq 0
$$

q.d.e.

Proposition $3 \Pi_{\text {free }}^{\frac{1}{N}}+\delta(1+\lambda)\left(V_{\text {in }}-V_{\text {out }}\right) \geq 0$ if and only if $\Pi_{\text {free }}^{\frac{1}{N}}+\delta(1+\lambda) \Pi_{\text {old }}^{\frac{1}{N}} \geq 0$

Proof. assume that the no-entry condition is verified. Then $V_{\text {out }}=0$. From no-exit verified we know that $V_{i n}=\frac{1}{1-\delta(1+\lambda)}\left(\Pi_{\text {free }}^{\frac{1}{N}}+\Pi_{\text {old }}^{\frac{1}{N}}\right)$, then substituting we get

$$
\Pi_{\text {free }}^{\frac{1}{N}}+\frac{\delta(1+\lambda)}{1-\delta(1+\lambda)}\left(\Pi_{\text {free }}^{\frac{1}{N}}+\Pi_{\text {old }}^{\frac{1}{N}}\right) \geq 0
$$

that is the same as

that is

$$
((1-\delta(1+\lambda))+\delta(1+\lambda)) \Pi_{\text {free }}^{\frac{1}{N}}+\delta(1+\lambda) \Pi_{\text {old }}^{\frac{1}{N}} \geq 0
$$

$$
\Pi_{\text {free }}^{\frac{1}{N}}+\delta(1+\lambda) \Pi_{\text {old }}^{\frac{1}{N}} \geq 0 .
$$

If $\Pi_{\text {free }}^{\frac{1}{N}}+\delta(1+\lambda)\left(V_{\text {in }}-V_{\text {out }}\right)<0 \Rightarrow V_{\text {in }}=\delta(1+\lambda) V_{0}+\Pi_{\text {old }}^{\frac{1}{N}}$. From no-entry verified we have $V_{\text {out }}=0$. Then substituting we get $\Pi_{f r e e}^{\frac{1}{N}}+\delta(1+\lambda) \Pi_{\text {old }}^{\frac{1}{N}}<0$. Assume now that no-entry is not satisfied. Then the no-exit is always true. Also we have

$$
V_{\text {out }}=\Pi_{\text {free }}^{0}+\delta(1+\lambda) V_{\text {in }}
$$

and from no-exit verified we get

$$
V_{i n}=\frac{1}{1-\delta(1+\lambda)}\left(\Pi_{\text {free }}^{\frac{1}{N}}+\Pi_{\text {old }}^{\frac{1}{N}}\right)
$$

then the no-exit condition becomes

$$
\Pi_{\text {free }}^{\frac{1}{N}}+\delta(1+\lambda)\left(\Pi_{\text {free }}^{\frac{1}{N}}-\Pi_{\text {free }}^{0}+\Pi_{\text {old }}^{\frac{1}{N}}\right) \geq 0 \Rightarrow \Pi_{\text {free }}^{\frac{1}{N}}+\delta(1+\lambda) \Pi_{\text {old }}^{\frac{1}{N}} \geq 0
$$

q.d.e. 


\section{Sub-GAme PeRfection}

In order to prove Lemma 3, we first show the following result:

Proposition 4 No one-stage deviation is profitable for an existing bank, if it does not induce the exit of some other bank.

Proof. Suppose bank $i$ deviates from $\hat{r}_{t}$ in period $t$. From the first order conditions we know that $\hat{r}_{t+1}$ does not depend directly on $s^{t}$ (the bank's market share in $t$ ), so that, as long as $N_{t}=N_{t+1}, \hat{r}_{t}=\hat{r}_{t+1}$. This implies that, unless bank $i^{\prime}$ s deviation induces a change in $N$, all banks will charge $\hat{r}_{t}$ in $t+1$. Then it is evident from the first order conditions that a one stage deviation cannot be profitable as long as it does not induce a change in $N$. q.d.e.

Then we have:

Corollary 2 No deviation with $r>\hat{r}$ can be profitable.

Proof. From the previous proposition we know that to be profitable a one-stage deviation has to induce a change in $N$. Given per period profits are a decreasing function of $N$, if a deviation is not profitable with $N_{t+1}=N_{t}$, then it cannot be profitable with $N_{t+1} \geq N_{t}$. This means that no $r>\hat{r}$ can represent a profitable deviation. q.d.e.

Now we can show:

Lemma 3 If $N=\bar{N}_{n o-e n t r y}$ then the proposed Nash equilibrium is also sub-game perfect.

Proof. From the previous corollary we know that a necessary condition for a deviation to be profitable is that it induces exit. If $N_{t}=\bar{N}_{n o-e n t r y}$ no deviation can induce other banks to exit. Even with a market share equal to zero, a bank will be indifferent between exiting and bidding for the free-market in period $t+1$. Then no profitable deviation exists. $\quad$ q.d.e. 


\section{The Perfect Test Case}

In this section I show that the main results of this paper hold when we relax the assumption that banks cannot distinguish between new firms and old firms rejected by other banks. As long as the procedure to discriminate is costly, asymmetric information represents a barrier to entry. Here I assume that banks can use a perfect test to evaluate firms credit-worthiness. ${ }^{1}$

Proposition 5 If (i) banks are able to perfectly screen potential clients, and (ii) the screening technology involves a cost $v$ per borrower, then the equilibrium market structure will be characterized by a finite number of banks.

Proof. For simplicity consider the case of an economy with a stationary borrower population. There is a population of mass 1 with new and old borrowers in equal proportions. The bank's objective function is

$$
\max _{r^{t}} \Pi_{f r e e}^{t}\left(r^{t}, r_{o}^{t}, s^{t-1}, N\right)+\delta\left[\Pi_{\text {free }}^{t+1}\left(r^{t+1}, r_{o}^{t+1}, s^{t}, N\right)+\Pi_{\text {old }}^{t+1}\left(r_{m}^{t+1}, N, s^{t}\right)\right]
$$

Here $v$ is the test cost and $c$ is the funds cost. The objective function becomes

$$
\begin{aligned}
& \max _{r} \frac{(r \theta-v-c)}{2}\left(\theta \cdot \frac{\left(r_{o}-r\right)-\delta \cdot\left(E\left(r_{o}^{t+1}\right)-E\left(r^{t+1}\right)\right)}{\tau \cdot(1-\delta)}+\frac{1}{N}\right) \\
& -\frac{v(1-\theta)\left(\frac{2}{N}-s_{i}^{t-1}\right)}{2} \\
& +\delta \frac{1}{2}\left(r^{t+1} \theta-v-c\right)\left(\theta \cdot \frac{\left(r_{o}^{t+1}-r^{t+1}\right)-\delta \cdot\left(E\left(r_{o}^{t+2}\right)-E\left(r^{t+2}\right)\right)}{\tau \cdot(1-\delta)}+\frac{1}{N}\right) \\
& -\delta \frac{1}{2}\left[v(1-\theta)\left(\frac{2}{N}-\theta \cdot \frac{\left(r_{o}-r\right)-\delta \cdot\left(E\left(r_{o}^{t+1}\right)-E\left(r^{t+1}\right)\right)}{\tau \cdot(1-\delta)}+\frac{1}{N}\right)\right] \\
& +\delta \theta \frac{1}{2}\left(r_{m}^{t+1}-c+\frac{\tau}{N}\right)\left(\theta \cdot \frac{\left(r_{o}-r\right)-\delta \cdot\left(E\left(r_{o}^{t+1}\right)-E\left(r^{t+1}\right)\right)}{r \cdot(1-\delta)}+\frac{1}{N}\right) \\
& -\delta \theta \frac{1}{2}\left[\frac{\tau}{2}\left(\theta \cdot \frac{\left(r_{o}-r\right)-\delta \cdot\left(E\left(r_{o}^{t+1}\right)-E\left(r^{t+1}\right)\right)}{\tau \cdot(1-\delta)}+\frac{1}{N}\right)^{2}\right]
\end{aligned}
$$

deriving with respect to $r$ we get the first order conditions

$$
\begin{gathered}
\frac{\partial O F}{\partial r}=\frac{\theta}{2}\left(\theta \cdot \frac{\left(r_{o}-r\right)-\delta \cdot\left(E\left(r_{o}^{t+1}\right)-E\left(r^{t+1}\right)\right)}{\tau \cdot(1-\delta)}+\frac{1}{N}\right)-\frac{1}{2 \frac{\tau}{\theta}(1-\delta)}(r \theta-c-v)-\frac{\delta \cdot(1-\theta) v}{2 \frac{\tau}{\theta}(1-\delta)} \\
+\frac{\delta \theta}{2(1-\delta) \tau}\left(-\theta\left(r_{m}^{t+1}-c+\frac{\frac{\tau}{\theta} \theta}{N}\right)\right)+\frac{\delta \theta^{2}}{2(1-\delta)}\left(\theta \cdot \frac{\left(r_{o}-r\right)-\delta \cdot\left(E\left(r_{o}^{t+1}\right)-E\left(r^{t+1}\right)\right)}{\tau \cdot(1-\delta)}+\frac{1}{N}\right)=0
\end{gathered}
$$

The second order conditions are satisfied

$$
\frac{\partial^{2} O F}{\partial r^{2}}=-\frac{\theta^{2}}{\tau(1-\delta)}-\frac{1}{2} \delta \frac{\theta^{3}}{\tau(1-\delta)^{2}}<0
$$

Then imposing symmetry and steady state, and assuming that firms do not have systematically biased expectations, we get the equilibrium interest rate

$$
\hat{r}=\frac{\tau(1-\delta)}{N(1+\delta) \theta}+\frac{c(1+\delta \theta)}{(1+\delta) \theta}+\frac{v(1-\delta+\delta \theta)}{(1+\delta) \theta}
$$

\footnotetext{
${ }^{1}$ Notice that with a perfect test we have to assume that it is not costly for old firms to be tested. Otherwise there is no-pure strategy equilibrium. Here $\mathbf{I}$ am only interested in generalizing my result, hence I just make this heroic assumption.
} 
the profit on the free market in equilibrium for a bank with $\frac{1}{N}$ market share is

$$
\Pi_{\text {free }}^{1 / N}=\frac{1}{2 N}\left(\theta \cdot\left(\frac{\tau(1-\delta)}{N(1+\delta) \theta}+\frac{c(1+\delta \theta)}{(1+\delta) \theta}+\frac{v(1-\delta+\delta \theta)}{(1+\delta) \theta}\right)-v-c-v(1-\theta)\right)
$$

and rearranging

$$
\Pi_{\text {free }}^{1 / N}=\frac{\tau(1-\delta)}{2 N^{2}(1+\delta)}-\frac{\delta(1-\theta) c}{2 N(1+\delta)}-\frac{(1+3 \delta-2 \delta \theta-\theta) v}{2 N(1+\delta)}
$$

plugging the equilibrium interest rate in the profit from old good firms, we get

$$
\begin{gathered}
\Pi_{\text {old }}^{1 / N}=\frac{\theta}{2} \cdot\left(\frac{1}{N}\left(r_{m}-c\right)+\frac{\tau}{2 N^{2}}\right) \\
\Pi_{\text {old }}^{1 / N}=\frac{\tau(2(1-\delta)+(1+\delta) \theta)}{4 N^{2}(1+\delta)}+\frac{(1-\delta+\delta \theta) v}{2 N(1+\delta)}+\frac{(1-\theta) c}{2 N(1+\delta)} \\
\Pi_{\text {free }}^{1 / N}+\delta \Pi_{\text {old }}^{1 / N} \geq 0
\end{gathered}
$$

Then the no-exit condition becomes

that is

then solving for $N$

$$
\Pi_{f r e e}^{1 / N}+\delta \Pi_{\text {old }}^{1 / N}=\frac{\tau(2(1-\delta)+\delta \theta)}{4 N^{2}}-\frac{(1+\delta)(1-\theta) v}{2 N} \geq 0
$$

The no-entry condition is

$$
\bar{N}_{n o-e x i t}=\frac{\tau(2(1-\delta)+\delta \theta)}{2(1+\delta)(1-\theta) v}
$$

where

$$
\Pi_{\text {free }}^{0}+\frac{\delta}{1-\delta}\left(\Pi_{\text {old }}^{1 / N}+\Pi_{\text {free }}^{1 / N}\right) \leq 0
$$

and

$$
\Pi_{\text {free }}^{0}=\frac{\tau}{2 N^{2}(1+\delta)}-\frac{\delta(1-\theta) c}{2 N(1+\delta)}+\frac{(-2-4 \delta+3 \delta \theta+2 \theta) v}{2 N(1+\delta)}
$$

then the condition is

$$
\Pi_{\text {free }}^{1 / N}+\Pi_{\text {old }}^{1 / N}=\frac{\tau(4+(1+\delta) \theta)}{4 N^{2}(1+\delta)}+\frac{(1-\delta)(1-\theta) c}{2 N(1+\delta)}-\frac{(4 \delta-3 \delta \theta-\theta) v}{2 N(1+\delta)}
$$

$$
\Pi_{\text {free }}^{0}+\frac{\delta}{1-\delta}\left(\Pi_{\text {old }}^{1 / N}+\Pi_{\text {free }}^{1 / N}\right)=\frac{\tau(2(1-\delta)+\delta \theta)}{4 N^{2}(1-\delta)}-\frac{(1-\theta) v}{N(1-\delta)} \leq 0
$$

and solving for $N$

q.d.e.

$$
\bar{N}_{n o-e n t r y}=\frac{\tau(2(1-\delta)+\delta \theta)}{4(1-\theta) v}
$$




\section{REFERENCES}

Allen, F. and D. Gale, (1995), "A Welfare Comparison of Intermediaries and Financial Markets in Germany and the US", European Economic Review, pp. 179-209.

Bhattacharya, S. and A, Thakor, (1993), "Contemporary Banking Theory" Journal of Financial Intermediation, 3, pp. 2-50.

Berger, A., Kashyap, A., and J. Scalise, (1995), "The Transformation of the US Banking Industry: what a long, strange trip it's been," Brooking Papers on Economic Activity, pp. 55-201.

Besanko, D., Thakor, A., (1992). "Banking Deregulation: Allocational Consequences of Relaxing Entry Barriers," Journal of Banking and Finance, pp. 909-932.

Broecker, T., (1990), "Credit-worthiness Tests and Interbank Competition", Econometrica, pp. 429452.

Chiappori, P.A., Perez-Castrillo, D., and T. Verdier, (1985), "Spatial Competition in the Banking System: Localization, Cross-Subsidies and the Regulation of Deposit Rates," European Economic Review, pp. 889-918.

Dell'Ariccia, G., Friedman, E., and R. Marquez, (1997), "Adverse Selection as a Barrier to Entry in the Banking Industry," MIT mimeo.

Dietsch, M., (1992), "Quel Model de la Concurrence dans l'industrie bancaire?", Revue Economique, pp. 228-260.

Greenbaum, S., Kanatas, G. and I. Venezia (1989), "Equilibrium Loan Pricing under the Bank-Client Relationship." Journal of Banking and Finance. Vol. 13, pp. 221-235.

Greenwald, B., (1986), "Adverse Selection in the Labour Market," Review of Economic Studies, pp. 325-347.

Gual, J., and D. Neven, (1992), "Deregulation of the European Banking Industry (1980-1991)," CEPR Discussion Papers No. 703.

Hannan, T., (1991), "Foundations of the Structure-Conduct-Performance Paradigm in Banking," Journal of Money, Credit and Banking, pp. 68-84. 
Hendricks, K., Porter, R., and C. Wilson, (1994), "Auctions for Oil and Gas Leases with an Informed Bidder and a Random Reservation Price," Econometrica, pp. 1415-1444.

Hoff, K., and J. Stiglitz, (1997), "Moneylenders, and bankers: price-increasing subsidies in a monopolistically competitive market," Journal of Development Economics, pp. 429-462.

Hoschka, T. (1993), Cross-Border Entry in European Financial Services, The MacMillan Press.

Matutes, C., and X. Vives, "Competition for Deposits, Fragility, and Insurance", Journal of Financial Intermediation, pp. 184-216.

Montgomery, J., (1991) "Market Segmentation and 1992: Toward a Theory of Trade in Financial Services, " in M.F.C. Whilborg and T. Willett, editors, Financial Regulation and Monetary Arrangements After 1992, pp. 173-199, Elsevier Science Publishers.

Padilla, J., and M. Pagano, (1997), "Endogenous Communication Among Lenders and Entrepreneurial Incentives", The Review of Financial Studies, pp. 205-236.

Pagano, M., and T. Jappelli, (1993), "Information Sharing in Credit Markets", Journal of Finance, pp. 1693-1718.

Petersen, M., and R. Rajan, (1995), "The Effect of Credit Market Competition on Lending Relationship", Quarterly Journal of Economics, pp. 407-443.

Riordan, M., (1993), "Competition and Bank Performance: a Theoretical Perspective", in C. Mayer and X. Vives, editors, Capital Markets and Financial Intermediation, pp. 329-348, Cambridge University Press.

Salop, S., (1979), "Monopolistic Competition with Outside Goods," Bell Journal of Economics, pp. 141-156.

Sharpe, S., (1990), "Asymmetric Information, Bank Lending, and Implicit Contracts: A Theoretical Model of Customer Relationship", Journal of Finance, pp. 1069-1087.

Steinherr, A., and Ch. Huveneers, (1994), "On the performance of differently regulated financial institutions: some empirical evidence", Journal of Banking and Finance, pp. 271-306.

Stiglitz, J. and A. Weiss, (1981), "Credit Rationing in Markets with Imperfect Information", American Economic Review, Vol.71, pp.393-410.

Sutton, J., (1991) Sunk Costs and Market Structure, The MIT Press, Cambridge, MA. 
Tirole, J. (1988), The Theory of Industrial Organization, The MIT Press, Cambridge, MA.

Van Damme, E., (1994), "Banking: A Survey of Recent Microeconomic Theory", Oxford Review of economic Policy, pp. 14-33.

Vives, X., (1991), "Banking Competition and European Integration", in A. Giovannini and C. Mayer, editors, European Financial Integration, pp. 9-31, Cambridge University Press.

Yannelle, M.O., (1995), "Price Competition among Intermediaries: The Role of the Strategy Space", DELTA Document No. 95-03. 